\title{
Reforma e Ecumenismo no pontificado do Papa Francisco
}

\author{
Reform and Ecumenism in the Pope Francis pontificate
}

\section{Elias Wolff*}

Pontifícia Universidade Católica do Paraná (PUCPR), Curitiba, PR, Brasil

\section{Resumo}

O pontificado do Papa Francisco aponta para um novo modo de a Igreja ser, tanto em sua organização interna, quanto em sua missão. Isso se dá por um projeto de reformas que seja "capaz de transformar tudo". Para tal, é necessário um verdadeiro caminho de conversão eclesial em três principais âmbitos: pessoal, estrutural e pastoral. Algumas instâncias da igreja são objeto direto de possíveis mudanças: a cúria romana, as conferências episcopais e o ministério petrino. A reforma dessas instâncias eclesiais tem implicações ecumênicas, uma vez que elas podem assumir um papel protagonista na promoção da unidade cristã.

Palavras chave: Igreja. Reforma. Papa Francisco. Ecumenismo.

EW: Doutor em Teologia, e-mail: elias.wolff@ucpr.br 


\section{Abstract}

Pope Francis pontificate points to a new way for the church to be in its internal organization and in its mission. This process is part of a Project based on reformations that may be "able to transform everything". Thus, a real ecclesial conversion path may be taken in three main aspects: personal, structural and pastoral. Some church realms are direct objects to possible changes: the Roman Curia, the bishop conferences and the ministry of Peter. These ecclesial realms reformation have ecumenical implications since they may get a leading role in the promotion of Christian unity.

Keywords: Church. Reformation. Pope Francis. Ecumenism.

\section{Introdução}

O momento atual da igreja católica é de um dinamismo eclesial há tempos não visto. O papa Francisco toma iniciativas que expressam claramente a sua intenção de revigorar o ser e o agir eclesial. Para isso, retoma o concílio Vaticano II em seus ensinamentos centrais, como a eclesiologia do povo de Deus, o protagonismo eclesial dos cristãos batizados, o valor das igrejas locais e das conferências episcopais, a relação da igreja com a sociedade, entre outros. Tudo faz parte de um decidido processo de reformas em "estruturas centrais" (EG 32) da igreja, levando uma significativa parte dos cristãos católicos à sensação que algo novo está acontecendo ou está por vir, com forte potencial de impacto positivo para a organização interna e a missão da igreja. Trata-se de "uma renovação eclesial inadiável" (EG 27-33). Isso não é sem resistências, o que não permite ingenuidade ou ufanismo. O papa sabe que muitos têm dificuldades "para aceitarem a custosa evolução dos processos" (EG 82). Mas o clima eclesial que se vive atualmente nos meios católicos é muito diferente daquele de pouco tempo atrás, no qual falar em necessidade de reformas poderia levar a suspeitas de toda ordem e, inclusive, ao obsequioso silêncio de quem ousasse questionar o status quo de segmentos da igreja.

As iniciativas do papa Francisco por reformas na igreja católica se expressam também nas suas relações com outras igrejas e as religiões. E 
as lideranças das diferentes igrejas, bem como das religiões, acompanham com atenção os seus resultados, na esperança que esse processo favoreça, no âmbito ecumênico, ao diálogo que visa progredir nos consensos teológicos que sustentam a comunhão na fé cristã.

\section{Instâncias eclesiais necessitadas de "uma reforma inadiável"}

O papa Francisco propõe reformas que sejam amplas e profundas na igreja católica, entendidas no horizonte da conversão em três níveis: pessoal, estrutural e pastoral. E reforma eclesial têm perspectiva missionária: "Sonho com uma opção missionária capaz de transformar tudo, para que os costumes, os estilos, os horários, a linguagem e toda a estrutura eclesial se tornem um canal proporcionado mais à evangelização do mundo atual do que à autopreservação" (EG 28). Dois elementos merecem destaque: a) a reforma eclesial diz respeito a todos na igreja, provocando a igreja "em saída" da zona de conforto, rompendo com uma "pastoral de conservação" e assumindo "uma necessidade generosa e quase impaciente de renovação" (EG 26). b) Essa renovação atinge tudo na igreja: a paróquia (EG 28), as comunidades de base, as pequenas comunidades, os movimentos e associações (EG 29), as igrejas particulares (EG 30), o ministério do bispo (EG 31) e o próprio papado (EG 32). Mudanças se fazem necessárias também na linguagem teológica (EG 27) e na espiritualidade (EG 78-80), atingindo elementos centrais: "Também as estruturas centrais da Igreja universal precisam ouvir esse apelo a uma conversão pastoral" (EG 32). A todos e a tudo o papa exorta a "serem ousados e criativos nesta tarefa de repensar os objetivos, as estruturas, o estilo e os métodos evangelizadores das respectivas comunidades" (EG 33).

Três instâncias aparecem como o foco de reformas na Igreja católica em nossos dias:

\section{A cúria romana}

A cúria romana é um organismo que tem como finalidade ajudar o papa a cuidar das questões da igreja universal (cf., Código de Direito Canônico, can. 360). Ela deve agir em sintonia e sob a autoridade do papa. 
Contudo, nem sempre as ações da cúria na realização de suas tarefas acontecem conforme a sua natureza e finalidade. Em dezembro de 2014 e 2015, o papa Francisco falou de um "catálogo de doenças curiais"1. E uma vez diagnosticada a "doença", o papa apresenta também a receita para curar: a reforma/conversão. Em dezembro de 2016, o papa propôs aos cardeais da cúria 12 critérios para a as reformas que pretende fazer, dentre os quais: a conversão pessoal, a conversão pastoral, a missionariedade (fé cristocêntrica), a atualização, a sobriedade, a subsidiariedade, a sinodalidade, a catolicidade ${ }^{2}$.

Emergem questões: como, concretamente, acontecerão na cúria romana reformas que tenham positivas implicações para toda a igreja? Como poderão ser efetivamente melhores as relações entre o papa e a cúria romana; a cúria e o sínodo dos bispos; o sínodo e todo o colégio episcopal, os bispos e os presbíteros, os presbíteros e toda a comunidade paroquial? Já foi perguntado "o que impediria ao papa de cessar de ser o responsável direto da cúria?” (LEGRAND, 2016, p. 176). E quem indaga sugere que o papa poderia ter um conselho para si mesmo, e a cúria outro conselho, que prestaria contas tanto ao papa quanto ao colégio dos bispos, "representado, por exemplo, pelo conselho do sínodo dos bispos junto ao papa" (LEGRAND, 2016, p. 180). Isso tem forte motivação pastoral se observado que a cúria não consegue resolver todas as questões de que trata, tanto no âmbito universal quanto sobre as igrejas locais.

\section{As conferências episcopais}

O papa Francisco tem ciência que as conferências episcopais foram, ao longo da história, destituídas dos meios que lhes permitem agir com autonomia e, ao mesmo tempo, na comunhão com Roma. Atualmente, elas apenas com dificuldades se fazem ouvir em suas solicitações e

10 papa citou: a planificação excessiva e o funcionalismo, um Alzheimer espiritual, a rivalidade e a vanglória, a divinização de líderes, a indiferença para com os outros, os círculos fechados, o lucro mundano, os exibicionismos. Disponível em: <http://w2.vatican.va/content/francesco/pt/speeches/2014/december/ documents/papafrancesco_20141222_curia-romana.html>.

2 Disponivel em: <http://w2.vatican.va/content/francesco/pt/speeches/2016/december/documents/papafrancesco_20161222_curia-romana.html>.

Rev. Pistis Prax., Teol. Pastor., Curitiba, v. 9, n. 2, 523-537, maio/ago. 2017 
contribuições às instituições centrais da igreja. A razão disso é que "ainda não foi suficientemente explicitado um estatuto das conferências episcopais que as considere como sujeitos de atribuições concretas, incluindo alguma autêntica autoridade doutrinal" (EG 32). Para superar tal situação, Francisco busca fortalecer o espírito de colegialidade, sinodalidade e subsidiariedade na igreja, pela prática de um real intercâmbio, diálogo e cooperação com/entre as Igrejas Locais. Entende Francisco que no modelo das antigas igrejas patriarcais, e retomando o n. 23 da Lumen gentium, "as conferências episcopais podem aportar uma contribuição múltipla e fecunda, para que o sentimento colegial leve a aplicações concretas" (EG 32). E conclui:

Penso, aliás, que não se deve esperar do magistério papal uma palavra definitiva ou completa sobre todas as questões que dizem respeito à Igreja e ao mundo. Não convém que o Papa substitua os episcopados locais no discernimento de todas as problemáticas que sobressaem nos seus territórios. Neste sentido, sinto a necessidade de proceder a uma salutar "descentralização" (EG 16).

A questão levantada por evangélicos ecumênicos é: "pode uma estrutura de poder vertical e dogmática sustentar-se sobre uma base democrática, participatória? A concepção eclesiológica do catolicismo não oferece espaço estrutural para uma proposta dialógica, democrática, participativa" (DIAS, 1996, p. 160). Constata-se que o Vaticano II afirmou a eclesiologia centrada na ideia de povo de Deus, superando a eclesiologia hierárquica até então: ubi episkopos ibi ecclesia. Mas isso não causou mudanças no exercício da autoridade episcopal na igreja católica, com efetiva participação dos cristãos batizados nas tomadas de decisões da vida da igreja.

\section{0 ministério petrino}

O papa Francisco tem consciência que reformas devem acontecer também no exercício do seu ministério. "Dado que sou chamado a viver aquilo que peço aos outros, devo pensar também numa conversão do papado" (EG 32). Reformas no papado devem acontecer no mesmo horizonte das reformas na cúria, nas conferências episcopais e em outras 
"estruturas centrais da Igreja universal" (EG 32). É o horizonte da conversão pastoral, ou seja, as reformas devem acontecer em função da missão evangelizadora da igreja em nosso tempo:

Compete-me, como Bispo de Roma, permanecer aberto às sugestões tendentes a um exercício do meu ministério que o torne mais fiel ao significado do que Jesus Cristo pretendeu dar-lhe e às necessidades atuais da evangelização. [...] Pouco temos avançado neste sentido (EG 32).

Sugestões são dadas para a reforma do primado petrino, como "tomar as suas decisões no âmbito de um consistório"; dar às conferências episcopais o direito de apresentar questões na ordem do dia do sínodo dos bispos, com "autoridade de decisão neste sínodo em algumas circunstâncias"; consultar os bispos antes de tomar decisões importantes; permitir que "um número qualificado de bispos" possam convocar um concílio; permitir o recurso à Santa Sé "contra uma sentença do romano pontífice" (LEGRAND, 2016, p. 188).

Isso exige uma profunda revisão teológica e jurídica do ministério petrino, sem alterar a essência da sua missão na igreja: "confirmar na fé". A questão é como expressar essa finalidade fundamental de forma harmônica com outras funções que o papa foi acumulando ao longo da história. O exercício do que é essencial no primado do bispo de Roma permite mudanças no que é periférico quanto à forma de exercer esse primado. Não são mudanças impossíveis, mas talvez não para o presente, de modo que o papa Francisco poderá, no máximo, preparar mudanças no primado que, se espera, sejam levadas adiante por seus sucessores.

Não houve, nestes pouco mais de quatro anos do pontificado de Francisco, mudanças canônicas, estruturais ou na jurisdição do ministério petrino. O papa argentino começou por mudar o seu modus operandi, o jeito de ser papa, com um estilo próprio, apresentando elementos tanto programáticos - para o projeto de reformas na igreja à luz do Vaticano II; quanto paradigmáticos - como horizonte teológico e pastoral onde se compreende a verdade da igreja "em saída" e a sua missão. Esses horizontes se expressam nas categorias de proximidade, misericórdia, 
cultura do encontro e do diálogo, cooperação, no âmbito social, ecumênico e inter-religioso.

\section{Implicações ecumênicas das reformas eclesiais no pontificado de Francisco}

O vínculo entre reforma e ecumenismo faz parte do projeto eclesial do Vaticano II (UR 6). Trata-se de uma revisão no ser e no agir da igreja, de modo que ela possa melhor expressar a sua identidade, natureza e missão. Isso foi bem explicitado como "limpar a própria casa" para torná-la "habitável" por todos. É clara a sua finalidade ecumênica:

Em que sentido? Pode-se responder com duas palavras: para que a casa seja "de todos", não apenas "aberta" a todos, mas "habitável" para cada um. Em outras palavras, para que todos os cristãos possam encontrar aí lugar e gozar de todas as formas legítimas de piedade, de espiritualidade, de vida eclesial, e não sejam obrigados a aceitar uma forma particular, mesmo que fosse a melhor, para ser verdadeiramente católicos (THILS, 1963, p. 267).

Os três espaços das reformas eclesiais propostas por Francisco têm significativos alcances ecumênicos.

\section{A cúria romana}

O papa é claro nos seus objetivos de reforma da cúria:

antes de mais nada, torná-la con-forme à Boa Nova que deve ser proclamada jubilosa e corajosamente a todos, especialmente aos pobres, aos últimos e aos descartados; con-forme aos sinais do nosso tempo e a tudo o que de bom alcançou o homem, para melhor atender às exigências dos homens e das mulheres que somos chamados a servir ${ }^{3}$.

Não é necessário muito esforço para perceber que isso tem implicações para toda a igreja e, de alguma forma para todas as comunidades cristãs: deixá-las mais conformadas ao Evangelho e aos sinais dos tempos

3 Disponível em: <http://w2.vatican.va/content/francesco/pt/speeches/2016/december/documents/papafrancesco_20161222_curia-romana.html>.Acesso em: 28 de jan. 2017. 
que interpelam por novos e atualizados modos de compreender, pregar e viver a Boa Nova do Reino. Era o que Lutero propunha em seu projeto de reforma: recentrar a Igreja em Cristo, em seu Evangelho. No âmbito católico, os doze critérios que o papa apresenta para a reforma da cúria em muito podem ser aplicados também para reformas em outros espaços eclesiásticos e na igreja como um todo. E a necessidade de "con-formar" as estruturas, instituições e doutrinas com o Evangelho é algo que diz respeito ao cristianismo como um todo.

Teólogos ecumênicos de diferentes igrejas observam com olhar esperançoso os progressos ecumênicos possíveis a partir das reformas na cúria romana. Sabem que "sejam quais forem as decisões tomadas no tocante à reforma da Cúria, terão repercussões nas relações entre as confissões cristãs" (ALTMANN, 2013, p. 134). O que se espera é que essas repercussões sejam positivas. E isso acontecerá na medida em que a cúria abandonar o seu estilo burocrático, legalista e concentrador - elementos que estão na raiz das tensões e conflitos com Lutero, Calvino e os demais reformadores. Também em nossos tempos é comum a impressão que o entrave maior para as relações ecumênicas (e inter-religiosas) não está, efetivamente, no papa, mas nas estruturas curiais. Papas como João XXIII e Francisco expressam a clara vontade de agilizar o processo de reconciliação com outras igrejas. Mas é perceptível que a cúria não tem o mesmo ritmo na caminhada ecumênica. E, o pior, não poucas vezes caminha em sentido paralelo ou até mesmo contrário. É o que se pode constatar entre as orientações ecumênicas e inter-religiosas do Vaticano II e a Declaração da Congregação para a Doutrina da Fé, Dominus Iesus (2000).

\section{Conferências episcopais e Igreja local}

No Novo Testamento, o termo igreja faz referência à sua dimensão local, no singular (Jerusalém, Corinto, Roma) ou no plural como "igrejas". Ao longo da história, a tradição católica privilegiou a dimensão universal da igreja para explicitar o sentido de comunhão. Há uma só Igreja fundada por Cristo, que se manifesta nas igrejas locais e na Igreja universal. "A Igreja de Cristo [...] é a Igreja Universal [...] que se torna presente e operante na particularidade e diversidade das pessoas, grupos, tempos 
e lugares" . A igreja local não é uma parte (pars) da Igreja universal, mas porção (portio) dela (CD 11) como povo de Deus, com todas as suas propriedades. Assim, a igreja local é a igreja universal em sentido pleno, embora esta não se esgote naquela. A eclesiologia protestante enfatiza ainda mais a igreja local, entendendo que cada comunidade ou congregação local é igreja num sentido pleno, que se realiza pela pregação do Evangelho e a administração dos sacramentos. Para os luteranos,

não lhe falta nada daquilo que faz de uma reunião de homens a Igreja: nem a pregação da palavra e a distribuição dos sacramentos... nem o ministério que, por ordem de Cristo e no lugar de Cristo, anuncia a Palavra, administra os sacramentos e guia a comunidade ${ }^{5}$.

Salvas as devidas especifidades eclesiológicas entre católicos e protestantes, o papa Francisco entende, no horizonte do Vaticano II, que cada Igreja Particular "é o sujeito primário da evangelização enquanto é a manifestação concreta da única Igreja num lugar da terra... é a Igreja encarnada num espaço concreto" (EG 30). Que alcance ecumênico pode ter essa proposta? Realçar o poder das igrejas de uma região, com um novo estilo administrativo e pastoral, pode favorecer o diálogo eclesiológico com as tradições eclesiais oriundas da Reforma, sustentadas na igreja local enquanto communio sanctorum. A eclesiologia da igreja local tem grande espaço no movimento ecumênico, como afirma a III Assembleia Plenária do Conselho Mundial de Igrejas, realizado em Nova Delhi (1961), ao propor como modelo de unidade da igreja a "unidade em cada lugar":

Cremos que a unidade que é simultaneamente vontade e dom de Deus para a sua Igreja, torna-se visível quando todos aqueles que em cada lugar são batizados em Cristo Jesus e o confessam como Senhor e salvador, são conduzidos pelo Espírito Santo a formarem uma comunidade plenamente comprometida, que confessa a mesma fé apostólica, que prega o mesmo Evangelho, que parte o mesmo pão, que se reúne na oração comum e que tem uma vida comunitária que brilha no testemunho e no serviço a todos; e quando, além disso, se encontram em comunhão com o conjunto

4 Congregação para a Doutrina da Fé, Communionis notio, n. 3.

5 Ci Católica-Luterana, “Chiesa e giustificazione”, EO, vol. III, n. 85. 
da comunidade cristã em todos os lugares e em todos os tempos, num modo em que o ministério e a qualidade de membro sejam reconhecidos por todos e todos possam, segundo as circunstâncias, agir e falar de comum acordo em vista dos compromissos aos quais Deus chama o seu povo (CMI, 2001, p. 250).

Assim, na diversidade de cada lugar as comunidades locais dos cristãos estão unidas na catolicidade da fé. A doutrina católica afirma que "a universal comunidade dos discípulos do Senhor... se torna presente e operante na particularidade e diversidade das pessoas, grupos, tempos e lugares" (Congregação para a Doutrina da Fé, 1992, n. 7). Isso contribui para progressos no mútuo entendimento da pluralidade de formas e contextos da realização da igreja. E tal é possibilitado pela ação do Espírito, quem "realiza a distribuição das graças e dos ofícios, e enriquece a Igreja de Jesus Cristo com múltiplos dons" (UR 2). O Espírito não propõe as diferenças como elementos de distanciamento de uma igreja em relação à outra, mas como caminhos para a comunhão eclesial, pelo que é "o princípio da unidade da igreja” (UR 2). Trata-se de um caminho a ser percorrido pelo diálogo que visa a "unidade na diversidade reconciliada". Essa e a compreensão do papa Francisco da meta do ecumenismo:

O Espírito Santo faz a diversidade na Igreja... o Espírito Santo não faz uniformidade!... É neste caminho que nós cristãos fazemos aquilo a que chamamos com o nome teológico ecumenismo: procuremos fazer com que esta diversidade seja mais harmonizada pelo Espírito Santo e se torne unidade ${ }^{6}$.

O papa usa uma figura geométrica para expressar a sua compreensão de unidade na diversidade:

Pensemos no poliedro: o poliedro é uma unidade, mas com todas as partes diversas; cada uma tem a sua peculiaridade, o seu carisma. Esta é a unidade na diversidade. É neste caminho que nós cristãos fazemos aquilo a que chamamos com o nome teológico ecumenismo: procuremos fazer com

6 Disponível em: <http://w2.vatican.va/content/francesco/pt/speeches/2014/july/documents/papafrancesco_20140728_caserta-pastore-traettino.html>. Acesso em: 04 mai. 2017. 
que esta diversidade seja mais harmonizada pelo Espírito Santo e se torne unidade... É este o nosso caminho, esta é a nossa beleza cristã7!

\section{0 papado}

Rever o exercício do ministério petrino é algo que diz respeito às aspirações por reforma na igreja ao longo da sua história. Desde os tempos de Constantino (séc. IV), a autoridade na igreja universal vem se concentrando na igreja local de Roma e, nela, tudo depende do papa, com sérias consequências para o exercício da colegialidade e da sinodalidade evangélicas. Isso tem consequências para as relações ecumênicas. Os papas Paulo VI e João Paulo II manifestaram a consciência de que de que o ministério petrino "constitui uma dificuldade para a maior parte dos outros cristãos" (UUS 88), o que lhes levou a pedir perdão ao Conselho Mundial das Igrejas (Paulo VI em 1969 e João Paulo II em 1984). João Paulo II propôs compreender o exercício do ministério petrino "em uma nova situação", de modo que ele seja "um serviço de amor reconhecido por uns e por outros" (UUS 95). O primado de Francisco segue nessa direção (EG 32). A “nova situação” possível leva à pergunta se isso poderia ter alguma extensão, para os governos das diferentes igrejas envolvida no diálogo com Roma, da participação que Francisco propõe para as Conferências Episcopais (EG 16). Não se trata apenas de uma aproximação no estilo de governo das diferentes igrejas, mas da possibilidade de uma ampla revisão também teológica e canônica do papado, de modo a favorecer uma real interação em forma de intercâmbio e de cooperação na missão de salvaguardar a unidade da igreja.

Três expressões ecumênicas no pontificado de Francisco: 1) mudanças no jeito de ser papa, que se distancia da imagem de um monarca que possui o poder supremo da igreja e age independente de qualquer outro órgão eclesial e qualquer outro membro da igreja, seja da hierarquia ou dos leigos. Essa imagem é criticada na Apologia da Confissão de Augsburgo: "Os nossos adversários gostariam talvez que a igreja fosse definida como uma monarquia exterior [...] na qual o pontífice romano deve ter um poder

7 Disponivel em: <http://w2.vatican.va/content/francesco/pt/speeches/2014/july/documents/papafrancesco_20140728_caserta-pastore-traettino.html>. Acesso em: 04 mai. 2017. 
ilimitado que ninguém tem o direito de discutir ou de colocar em juízo" (Enchiridion Oecumenicum, 1996, p. 168). 2) Junto às mudanças no estilo, Francisco apresenta mudanças na mentalidade que sustenta a autoridade papal, o que se constata em sua linguagem e suas atitudes situadas no horizonte da sinodalidade, colegialidade e subsidiariedade. Certamente o novo modo de exercer o ministério petrino na igreja "em saída" dialoga melhor com aquelas formas de governo que nas outras igrejas se realizam de forma sinodal e conciliar. 3) A compreensão da sua missão como um serviço à unidade dos cristãos (EG 32; 244-246), favorecendo também o diálogo inter-religioso na promoção e defesa de todas as formas de vida, humana e do planeta (LS 8-9;14; 92; 200-201;2014; 221). Para tanto, é preciso ter claro qual é a essência desse ministério: desenvolver a missão de manter "toda a igreja na unidade da fé e da comunhão" (Denzinger-Hünermann, n. 3051; LG 18; UUS 88). Esse aspecto do primado é imutável. Mas é preciso compreender também que o serviço à fé de "toda a igreja" tem alguma necessidade de transcender estruturas e instituições de uma tradição eclesial apenas. A catolicidade da fé não se realiza plenamente enquanto as igrejas estiverem divididas por doutrinas e instituições que impedem a visibilidade da Igreja una e única de Cristo. Assim, a essência do ministério petrino está em "confirmar os irmãos na fé” (Lc 22,31), mesmo os que não se encontram atualmente nas estruturas eclesiásticas onde o papa exerce um poder efetivo. Evidentemente, muitas questões surgem sobre o possível reconhecimento de uma autoridade única para todas as igrejas. Das respostas que podem ser dadas, é importante observar que não está em questão o "ministério petrino" concedido por Cristo a Pedro, tal como os Evangelhos apresentam (Mt 16, 18-19; Jo 20,23; 21, 15-17), mas a interpretação e organização prática do exercício desse ministério. O que se questiona é o modo e o sujeito desse ministério. E sobre isso as igrejas ainda têm muito que dialogar.

\section{Fidelidades ecumênicas das reformas eclesiais}

Há um vínculo estreito entre reforma, missão e ecumenismo, no horizonte de uma conversão pastoral que coloca a igreja em permanente processo de "saída" para o diálogo e a cooperação com a sociedade, com as diferentes religiões e as diferentes igrejas. 
Esse trinômio de reforma, missão e ecumenismo expressa três fidelidades ecumênicas no pontificado do papa argentino: 1) ao Evangelho do Reino: é para poder pregar o Evangelho de modo crível e com plausibilidade de acolhida na sociedade atual que se fazem necessárias reformas na igreja. O Evangelho mostra a precariedade das estruturas eclesiais, com uma "disfunção atual entre a prática institucional da igreja católica e a mensagem de Jesus Cristo da qual ela pretende ser testemunha" (DUCQUOC, 2001, p. 20). Ao mesmo tempo que as instituições servem à mensagem evangélica do Reino, também podem dificultar a sua explicitação. E a superação disso é uma tarefa ecumênica. As igrejas precisam, juntas, buscar o consenso sobre como deve ser a Igreja dos Evangelhos, na coerência entre o seu modus essendi e o seu modus operandi enquanto testemunhas do Reino. 2) Ao tempo presente: o processo de reformas no pontificado de Francisco redimensiona o pensar teológico e a ação evangelizadora da igreja como forma de responder às exigências que o tempo de hoje apresenta para a fé. E uma das marcas do tempo atual é o pluralismo eclesial. As reformas precisam responder às exigências dessa realidade plural. E para isso, a igreja católica não pode se estagnar e se manter presa a formulações conceituais e modelos de ação prática que talvez, outrora, tenham sido válidos, mas que no presente exigem revisão e aggiornamento - e se necessário for, abandono mesmo (cf., EG 33; 43). Não como prejuízo à própria identidade, mas na construção de uma identidade relacional e de comunhão. 3) Ao concílio Vaticano II: esse concílio afirmou que a igreja tem necessidade de uma "reforma perene", mudanças, conversão (UR 6; LG 8). E as reformas conciliares acontecem de modo a favorecer a prática ecumênica da igreja católica. É como retomada do Vaticano II, "discernindo os sinais dos tempos" (GS 1), que as reformas acontecem como mudanças na continuidade, e o papa Francisco está ciente que "estamos muito atrasados nisso" (FRANCISCO, 2013, p. 75). Nesse caminho vai a igreja "em saída", num processo de "conversão pastoral" em perspectiva missionária (EG 25-26), trilhando os caminhos do ecumenismo.

\section{Considerações finais}

As igrejas integradas no movimento ecumênico sabem que mudanças podem e devem ocorrer em suas doutrinas e estruturas. Essas mudanças 
não são apenas frutos do diálogo que as igrejas realizam, mas uma exigência do conteúdo desse diálogo, o Evangelho. É o Evangelho que exige mudanças nas igrejas, e o diálogo entre elas é um meio imprescindível para que cheguem ao consenso sobre o que e como mudar. A finalidade das mudanças e reformas é a comunhão na fé em Cristo e a fidelidade no testemunho comum do Evangelho. O diálogo abre a mens teológica de cada igreja para a compreensão que as outras igrejas têm do Evangelho. Acontece, então, a interação, o intercâmbio e a ajuda mútua na compreensão do projeto que Deus manifesta em Cristo, para a sua Igreja e para o mundo. E na medida em que as igrejas entram em consenso na hermenêutica e na vivência desse projeto, elas vão se transformando internamente para comungarem na única Igreja de Cristo. As igrejas enfrentam essas transformações na confiança que elas favoreçam para uma melhor compreensão e expressão da verdade dos Evangelhos. Dessa forma, há uma relação sincrônica entre o aprofundamento da convicção ecumênica e as transformações eclesiásticas. Ser ecumênico é, então, colocar-se na dinâmica de reformas profundas, superando todo imobilismo e enrijecimento que impossibilita ver as oportunidades dos tempos para o ser da igreja hoje.

\section{Referências}

ALTMANN, W. "Implicaciones ecuménicas da reforma da cúria". Concilium, 5, p. 133-142, 2013.

APOlOGIA DA CONFISSÃO DE AUGSBURGO. In: Livro de Concórdia. Porto Alegre: Concórdia, São Leopoldo: Sinodal, 1981, p. 97-304.

CÓDIGO DE DIREITO CANÔNICO. São Paulo: Loyola, 1983.

COMMISSIONE INTERNAZIONALE CATTOLICO-LUTERANA. Chiesa e giustificazione. In: Enchiridion Oecumenicum, vol. III, Bolonha: EDB, p. 551-696.

CONCÍLIO VATICANO II. Lumen gentium. In: Documentos do Concílio Vaticano II. São Paulo: Paulus, 2007, p. 101-192.

CONCÍLIO VATICANO II. Unitatis redintegratio. In: Documentos do Concílio Vaticano II. São Paulo: Paulus, 2007, p. 215-239. 
CONCÍLIO VATICANO II. Christus Dominus. In: Documentos do Concílio Vaticano II. São Paulo: Paulus, 2007, p. 241-275.

CONGREGAÇÃO PARA A DOUTRINA DA FÉ. Communionis notio. In: SEDOC 25, 262-272, 1992.

CONGREGAÇÃO PARA A DOUTRINA DA FÉ. Dominus Iesus - Dichiarazione circa l'unicità e l'universalità salvifica di Gesù Cristo e della Chiesa. Roma: Libreria Editrice Vaticana, 2000.

DIAS, Z. M. “Prática pastoral e prática política”. In: KOINONIA, Por Uma Nova Teologia Latino-Americana. São Paulo: Paulinas, 1996. p. 151-166.

DUCQUOC, C. Credo la Chiesa - Precarietà istituzionale e Regno di Dio. Bolonha: Queriniana, 2001.

HÜNERMANN, P; DENZINGER, H. (ed.). Enchiridion symbolorum. Bolonha: EDB, 1991.

JOÃO PAULO II. Ut Unum Sint. São Paulo: Paulinas, 1995.

LEGRAND, H. "La comunione sinodale come chiave del rinnovamento del popolo di Dio". In: SPADARO, Antonio/GALLI, Carlos Maria, La Riforma e le Riforme nella Chiesa. Brescia: Queriniana, 2016, 159-188.

THILS, G. Histoire doctrinale du mouvement oecuménique. Louvain: Warny, 1963.

FRANCISCO. "Discurso aos bispos responsáveis do Conselho Episcopal LatinoAmericano”. In: SEDOC, v. 46, n. 359 p. 73-80, 2013.

FRANCISCO. Evangelii gaudium. São Paulo: Paulinas/Loyola, 2013.

FRANCISCO. Laudato si'. São Paulo: Paulinas, 2015.

Recebido: 03/03/2017

Received: 03/03/2017

Aprovado: 02/06/2017

Approved:06/02/2017 
